\title{
CREATING APPROPRIATE GRAPHICS FOR BUSINESS SITUATIONS
}

\author{
Susan M. Katz \\ North Carolina State University
}

CHARTS AND GRAPHS are ubiquitous in business documents, and most students in my business communication courses are well aware that they need to be able to create many different types of data representation. Most of them have had a great deal of experience working with spreadsheet applications, and they know how to manipulate data and present them in the various forms permitted by their software. However, they don't always understand how to make the most appropriate choice among those forms for a particular situation. For example, they often use a pie chart when a bar graph would be more informative or a bar graph when a line graph would make the data's meaning more obvious.

To assist students in recognizing the salient features of charts and graphs, I provide them with a collaborative in-class activity that asks them not only to create a set of visuals but also to justify their choices to their classmates. The activity begins with distribution of a mini-case study, presented below, that leads to the creation of two visuals. After the students have had time to create the visuals, each group presents its work to the class, explaining the reasoning behind its presentation. The discussion that ensues during the "justification" part of the activity consistently improves the students' understanding of the advantages and disadvantages of the various forms that data representations can take.

\section{The Mini-Case Study}

Assume that you work for a local nonprofit organization with the following income and expenses for 2006 (see Table 1). As directors of the organization, you are responsible for bringing in more money and must present the past year's financial information to two groups of people, described in the following scenarios.

- Within the community is a core group of consistent contributors who give the same amount each year, although the cost of running your organization continues to go up. You must convince these contributors

Business Communication Quarterly, Volume XX, Number X, Month XXXX xx-xx

DOI: $10.1177 / 1080569907312877$

(C) 2008 by the Association for Business Communication 
Table 1 Organizational Income and Expenses in the Mini-Case Study

\begin{tabular}{|c|c|}
\hline Income & Expenses \\
\hline Government grants: $\$ 375,000$ & $\begin{array}{l}\text { Program services (money spent on the } \\
\text { actual mission of the organization): } \\
\$ 741,935\end{array}$ \\
\hline $\begin{array}{l}\text { Fees for services provided by your } \\
\text { program: } \$ 273,467\end{array}$ & $\begin{array}{l}\text { Administrative costs (salary and expenses } \\
\text { to run the organization): } \$ 88,500\end{array}$ \\
\hline Contributions: $\$ 114,763$ & Miscellaneous: $\$ 5,230$ \\
\hline \multicolumn{2}{|l|}{ Special events: $\$ 58,450$} \\
\hline \multicolumn{2}{|l|}{$\begin{array}{l}\text { Sale of products produced by } \\
\text { participants in your } \\
\text { program: } \$ 12,468\end{array}$} \\
\hline Total income: $\$ 834,148$ & Total expenses: $\$ 835,665$ \\
\hline
\end{tabular}

to give additional funds during your presentation at the annual fundraising banquet. You need to create graphic representations of financial data that will convince the contributors of the need for additional funds and that will reassure them that the money they have given in the past has been spent wisely.

- Your organization is eligible to apply for a new grant from a federal government agency. You have to write a proposal explaining why your organization needs the money and demonstrating that it is fiscally responsible. There is a strict page limit, so you must present financial information concisely, but in enough detail to make a strong case.

\section{The Instructions}

I ask the students to work in groups of two or three to create graphic representations of the financial data for the presentation and the proposal. I let them know that they will need to justify their choice of visuals on the basis of the audience, circumstances, and purpose for each scenario.

Depending on the classroom situation (traditional or computer), the students can either sketch out the visuals by hand or produce them on a computer. If we're not working in a computer classroom, I provide paper (if the room has a document projector) or transparency film (if the room has an overhead projector) and markers. If we are in a computer classroom, students can enter the data into a spreadsheet and produce graphics that can be projected. 
Typically, I give the students about 30 minutes to produce their graphs. We use the remainder of the class period (in our case, an additional 45 minutes) for the presentation, justification, and discussion of their visuals.

\section{The Results}

My students typically enjoy this exercise. Although there is no one right way to present the information, they are quite good at recognizing which graphics do the job best. While some groups do better jobs than others, this disparity is beneficial, because it allows the opportunity for students to compare the various options and discuss why they would choose particular types of graphs or charts for particular situations. In general, my students and I have come to the following conclusions:

- For the community group, the graphics should be fairly simple. The information will be presented at a banquet, so no one will be in the mood for a lengthy financial presentation. To demonstrate the need for additional funds, a bar graph showing the total income and total expenses makes a clear point that there is a shortfall. To show that the money has been spent wisely, a pie chart with the three types of expenses demonstrates clearly that the bulk of the money is going to program services.

- For the federal agency, the students usually understand that they need to provide much more detail. A bar graph showing the sources of income demonstrates the importance of government grants but also shows that the organization does not rely solely on government support. A pie chart is probably still the best way to show expenses, because there are only three items, and a pie chart is so effective at showing that a big "piece of the pie" goes to program services. However, students sometimes argue that a second bar graph would make sense for consistency of presentation. Another option is to simply use a table of income and expenses, as is found in a typical annual report.

\section{Further Opportunities}

If time permits, this activity can be expanded to incorporate further discussions and additional activities or homework assignments. For example, students frequently recognize that the case study is 
minimalist - that in a real situation, the organization would be likely to present its contributors with several years' worth of data so that they could show trends in contributions, spending, and administrative costs. Students can be asked to discuss how this would affect their visual presentation of data. To take it one step further, they can be asked to research an existing nonprofit organization's finances and, using actual financial data, produce visual representations appropriate for either scenario.

Another way to expand this activity is to focus on the need for additional funds. In the grant application scenario, an interested organization would likely want to provide information about why it needs the requested funds in greater detail than can be assembled on the basis of the scant data provided for the activity. Students can be asked to choose an existing nonprofit organization and produce a more detailed grant application, in which they answer questions such as "What is this new program?" "What are the anticipated costs?" and "What benefits will result?" They would also need to make decisions about how to present all this new information.

With the current emphasis on service learning at many universities and within many business communication courses, this type of activity can also supplement the work that students are doing within their actual service learning settings. Instructors can encourage students to share with the class the types of visuals that they are creating for their organizations and to justify their decisions about those visuals.

Susan M. Katz is associate professor of English at North Carolina State University, where she teaches graduate and undergraduate courses in business and technical communication. Her research interests include the scholarship of teaching and learning, the intersection of verbal and visual rhetorics, and the role of boundary spanners in high-tech environments. Address correspondence to Susan M. Katz, N. C. State University, Department of English, Campus Box 8105, Raleigh, NC 27695: email: smk@unity.ncsu.edu. 